\title{
RAINFALL AS A CAUSE OF MECHANICAL DAMAGE TO PSEUDOCYPHELLARIA RUFOVIRESCENS IN A NEW ZEALAND TEMPERATE RAINFOREST
}

Lichens, like all poikilohydric plants, have a metabolism that is dependent on external moistening from their environment. In the case of green algal lichens high humidities may be sufficient for positive net photosynthesis to occur (Lange et al. 1993a). For these plants water stress is usually taken to mean a lack of water (Kappen 1988; Rundel 1988) but it can also mean an excess of water that leads to depressed $\mathrm{CO}_{2}$ exchange because of increased diffusion resistances at high thallus water contents (Lange \& Tenhunen 1981; Kershaw 1985). Rather than this being an unusual occurrence, Lange et al. (1993b) found reduced $\mathrm{CO}_{2}$ exchange at thallus supra-saturation to be present over long periods in the temperate rainforest of north-eastern New Zealand.

In addition to the negative effects of excess water on the photosynthetic $\mathrm{CO}_{2}$ uptake of lichens, we have found that raindrops can produce mechanical damage to lichen thalli. In the course of field measurements on the photosynthetic behaviour of lichens of the Urewera National Park, North Island of New Zealand, we experienced a period of heavy rain. The rainfall, which was unusually high even for the locality, peaked on November 4 and 5 with 175 and $173 \mathrm{~mm}$ per day, respectively. During and after the rain the forest litter was found to contain a large number of lichens that had been torn off trees by the rain. Those most frequently found were members of the foliose lichen genera Pseudocyphellaria and Sticta, for example $P$. faveolata, $P$. rufovirescens, $S$. latifrons, $S$. filix. During the rainfall period gas-exchange measurements were being carried out continuously on a variety of lichen species. For each lichen, young thallus lobes were removed and mounted in small wire baskets to facilitate handling. Between measurements, the baskets, with included lichens, were exposed on a moss-covered log in a close approximation to their natural situation. As the heavy rainfall continued it was noticed that the upper cortex of one species, $P$. rufovirescens, was becoming progressively removed. Close observation revealed that the damage was due to the mechanical impact of raindrops. The erosion was caused by the peeling off of the upper layers, often initiated by a superficial crack, starting in the central parts of the lobes. Small flakes, a few millimeters in size, then became loosened at the sides of the damaged area and progressively extended to cover large parts of the lobes (Fig. 1). The centre of the lichen was less affected by peeling than the younger lobes. Following the initial discovery, a careful survey was made of lichens growing on surrounding trees. The damage was found to be widespread but to occur on only the same species that was damaged in the experimental baskets, namely $P$. mufovirescens.

A closer study of the internal morphology of the species revealed that, in susceptible areas of the lichen thallus, the connection between the medulla and algal layers was composed of many fewer hyphal strands than found between the algal layer and upper cortex, or between the medulla and lower cortex (Fig. 2). This weak contact between medullary and algal layers appears to be the reason for the susceptibility of the upper thallus to peel under the 


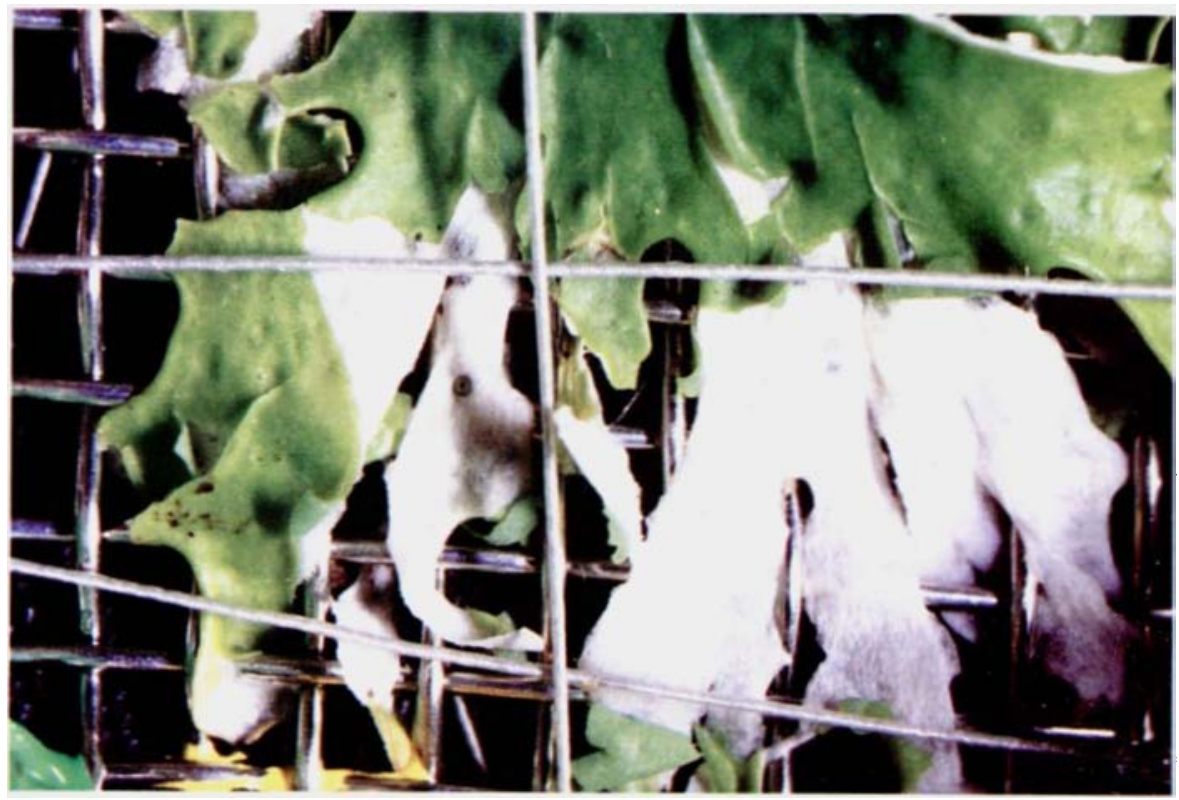

FIG. 1. Pseudocyphellaria mufovirescens, experimental specimen mounted in a wire basket $(4 \mathrm{~cm}$ diam.) and fixed by a thin wire. The white areas are those where the upper cortex, together with the algal layer, peeled off by the activity of heavy rain, exposing the white medullary layer. The intact thallus surface appears green. Scale $=2 \mathrm{~mm}$.

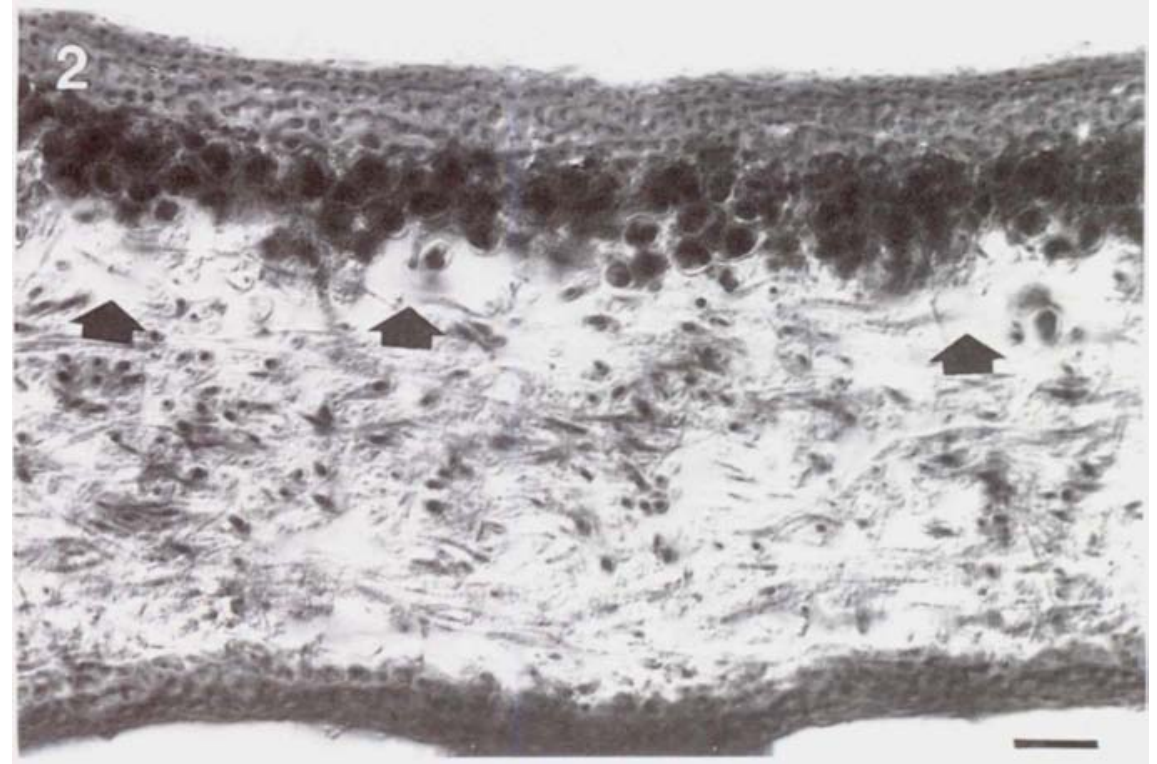

FIG. 2. Section of $P$. nufovirescens showing paraplectenchymatic upper cortex, algal layer, zone of weak hyphal connection (arrow), medulla and lower cortex. Scale $=20 \mu \mathrm{m}$. 
influence of a strong mechanical factor such as heavy rain. The zone can also be seen in the pictures taken by Renner \& Galloway (1982, fig. $2 a \& b$ ) both in $P$. rufovirescens, and the cyanobacterial partner of the photosymbiodeme, $P$. murrayii. A zone of weak contact between algal layer and the underlying medulla can occasionally be found in other rainforest species such as $P$. homoeophylla and $P$. pubescens. However, both of these latter species have an upper cortex twice as thick (mean $47 \mu \mathrm{m}$ ) as found in $P$. rufovirescens (mean $27 \mu \mathrm{m}$ ) and never showed any peeling damage.

Peeling of the upper thallus layers was observed to be worse on the rare occasions when the lichen grew flat on the substratum, whereas damage was less frequent when the thalli had space to swing away from the impact of raindrops. Thus, the lower rate of rainfall damage expected when thalli are less exposed to incoming raindrops on vertical surfaces or hang relatively freely from branches, might well explain the preference for these habitats by $P$. rufovirescens in the Urewera forest.

\section{REFERENCES}

Kappen, L. (1988) Ecophysiological relationships in different climatic regions. In Handbook of Lichenology, vol. II (M. Galun, ed.): 37-100. Boca Raton: CRC Press.

Kershaw, K. A. (1985) Physiological Ecology of Lichens. Cambridge: Cambridge University Press.

Lange, O. L. \& Tenhunen, J. (1981) Moisture content and $\mathrm{CO}_{2}$ exchange of lichens II. Depression of net photosynthesis in Ramalina maciformis at high water content is caused by increased thallus carbon dioxide resistance. Oecologia 51: 426-429.

Lange, O. L., Büdel, B., Meyer, A. \& Kilian, E. (1993a) Further evidence that activation of net photosynthesis by dry cyanobacterial lichens requires liquid water. Lichenologist 25: 175-189.

Lange, O. L., Büdel, B., Heber, U., Meyer, A., Zellner, H. \& Green, T. G. A. (1993b) Temperate rainforest lichens in New Zealand: high thallus water content can severely limit photosynthetic $\mathrm{CO}_{2}$ exchange. Oecologia 95: 303-313.

Renner, B. \& Galloway, D. J. (1982) Phycosymbiodemes in Pseudocyphellaria in New Zealand. Mycotaxon 16: 197-231.

Rundel, P. W. (1988) Water relations. In Handbook of Lichenology, vol. II (M. Galun, ed.): 17-36. Boca Raton: CRC Press.

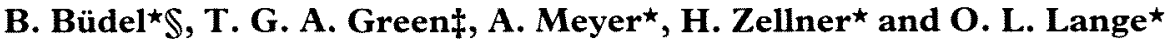

*Julius-von-Sachs-Institut für Biowissenschaften der Universität Würzburg, Mittlerer Dallenbergweg 64, D-97082 Würzburg, Germany.

$\ddagger$ Department of Biological Sciences, University of Waikato, Private Bag, Hamilton, New Zealand. Corresponding author, present address: Forschungsinstitut Senckenberg, Außenstelle Lochmühle, D-63599 Biebergemünd, Germany. 
